\title{
Histochemical study of alkaline phosphatase enzyme in gallbladder containing cholesterol stones
}

\author{
Luma I. Al-Allaf ${ }^{a}$, Mohammed Taib Taher ${ }^{a}$, Samir B. Al-Deen Al-Mukhtar ${ }^{b}$, Leka H. Al-Dulaimy ${ }^{c}$ \\ From the ${ }^{a}$ Department of Anatomy, College of Medicine, University of Mosul, ${ }^{b}$ Department of Biochemistry, Nineveh College of \\ Medicine, University of Mosul, 'Department of Biology, College of Raring for Girls, University of Mosul, Mosul, Iraq. \\ Correspondence: Luma I. Al-Allaf'. Lumaallaf1971@yahoo.com. \\ (Ann Coll Med Mosul 2013; 39 (2): 166-171). \\ Received: $7^{\text {th }}$ Oct. 2012; Accepted: $19^{\text {th }}$ May 2013.
}

\section{ABSTRACT}

Objective: To study the alterations in the expression pattern of alkaline phosphatase (ALP) in gallbladder mucosa in cases of cholelithiasis (cholesterol type) in order to find its role as an indicator of functional alteration in gall bladder mucosa in these cases.

Materials and methods: A prospective study was conducted over a period of 2 months started from July $1^{\text {st }}$ 2010 to September $1^{\text {st }} 2010$ at the laparoscopic unit in Al-Jumhori Teaching Hospital, Mosul, Iraq, and the Laboratory of postgraduate studies at the Department of Anatomy, Histology and Embryology, College of Medicine, University of Mosul. Analysis of the sections which were obtained from twenty-two surgically resected gallbladder specimens using laparoscope was done. Mean age was $50.5 \pm 2.1$ years (range 21-77), while the male:female ratio was 1:6. Clinical details were retrieved from the records. The cholecystectomy specimens that were received were fixed in $10 \%$ formalin. The findings on gross examination were noted, and the stones recovered from the gallbladder were analyzed by chemical examination. Multiple sections were taken from each cholesterol stone-containing gallbladder (body, neck, and fundus) for paraffin blocks and were examined after staining with hematoxylin and eosin (H\&E). Microscopic examination was done to assess the type of histological changes. To evaluate the enzymatic activity of alkaline phosphatase, sections were stained using alkaline phosphatase stain (Gomori's method- Cobalt).

Results: Light microscopic examination using haematoxylin and eosin (H\&E) revealed that 13 (59.09\%) out of 22 cases were diagnosed as cholerterosis, while sections obtained from $3(13.6 \%)$ out of 22 cases showed inflammation. Rokitansky-Aschoff sinuses were noticed in $6(27.27 \%)$ out of 22 cases. Using alkaline phosphatase stain (Gomori's method- Cobalt), the amount of alkaline phosphatase activity varied considerably among the different areas in the same sections, and often among different areas of the same layer of gallbladder, thus making the assessment difficult. However, this study showed $14(63.63 \%)$ out of 22 cases with moderate reaction to ALP stain in the mucosa, while $8(36.36 \%)$ cases showed weak to negative reaction to that stain.

Conclusion: The changes in ALP localization patterns may represent functional alterations either preceding or running concurrently with morphological damages in gallbladder with cholesterol stones. Futural studies will be recommended to localize ALP with different gallbladder disorders especially on ultrastructural, immunohistochemical, and biomolecular levels.

Keywords: Gallstones, histochemistry, alkaline phosphatase.

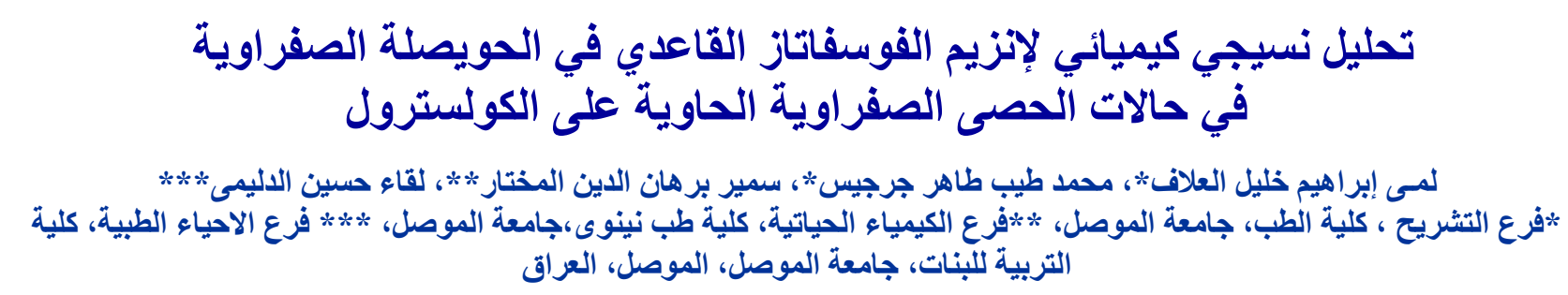

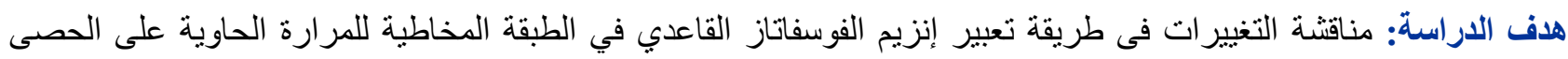
(نوع الكوليسترول) لغرض إكتشاف أي دور له كمؤشر للتغيرات الوظيفية فى خلايا الطبقة المخاطية في تللك الحالات. 


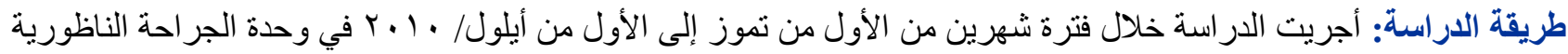

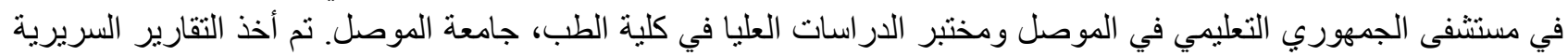

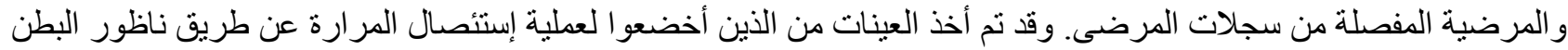

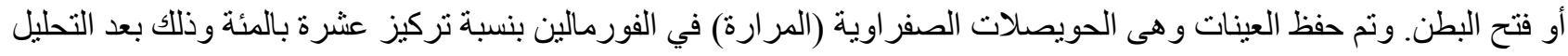

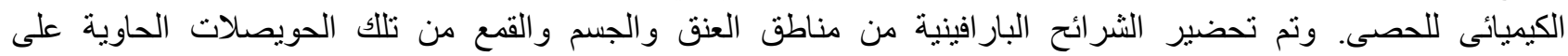

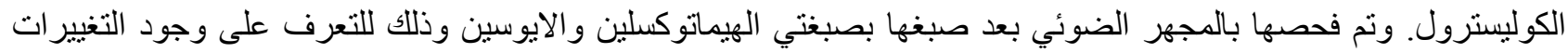

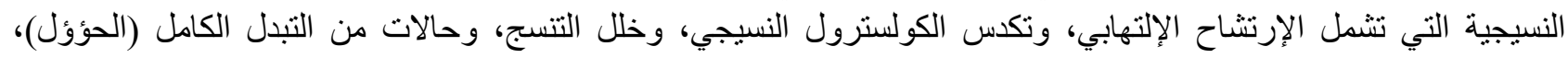

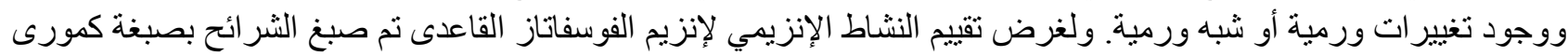
كوبلت.

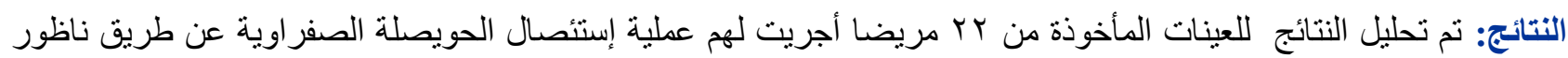

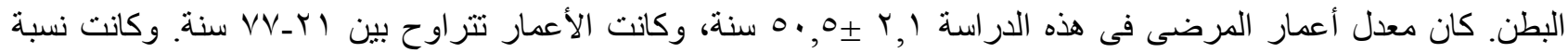

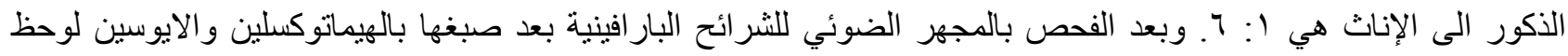

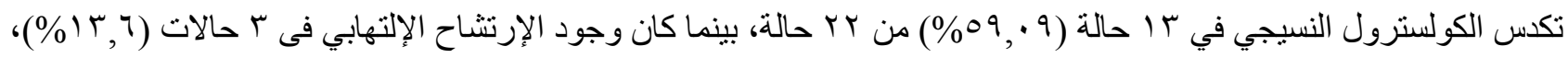

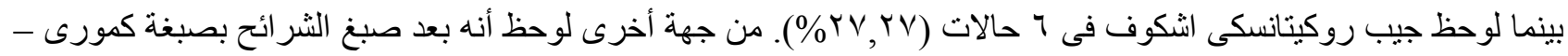

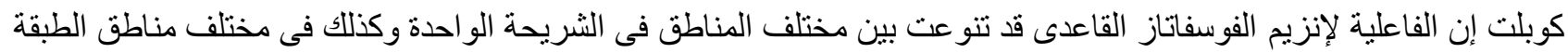

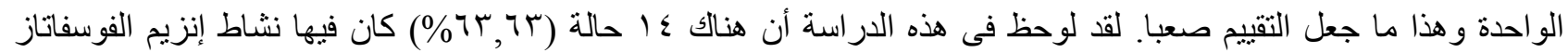

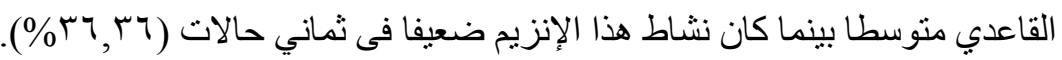

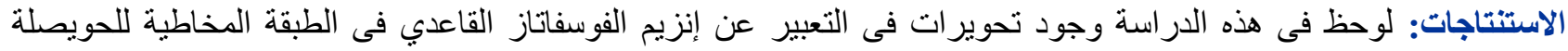

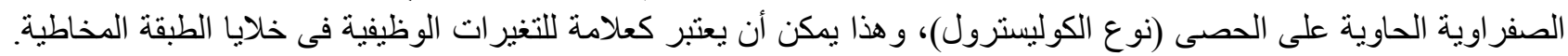

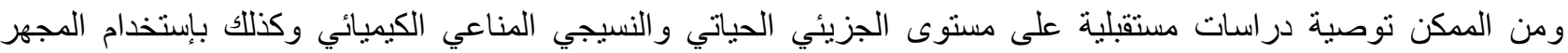

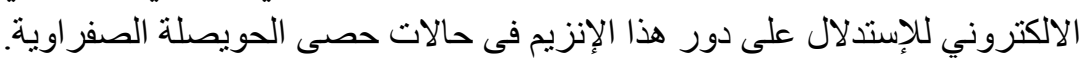

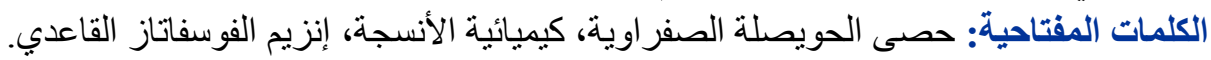

\section{INTRODUCTION}

C holesterol gallstones are one of the most prevalent and most costly digestive diseases in the world. ${ }^{1,2}$ The main function of the gallbladder is to concentrate bile by the absorption of water and sodium. ${ }^{3,4}$

The exact pathogenesis of gallstones remains poorly understood, ${ }^{3}$ and it has been reported that gallstones disease could be due to multiple causes. ${ }^{5,6}$ Moreover, there is considerable evidence indicating that patients with gallstone have altered gallbladder functions with respect to secretion, absorption and inflammation in the mucus membrane when compared with gallstonefree patients. ${ }^{7-9}$ There is mounting evidence that oxidative stress or an imbalance in the oxidant/antioxidant activity plays a pivotal role in these functional alterations. The abnormalities of gallbladder epithelial function has been involved in gallstone formation especially cholesterol type..$^{10-12}$ The data in several studies showed that the high level of oxidative stress may be related to altered activity of functional enzymes in mucosal cells including antioxidant enzymes such as catalase, glutathione peroxidase, glutathione transferase and glutathione reductase, in addition to the activity levels of alkaline phosphatase (ALP). ${ }^{13,14}$

ALP encompasses a group of heterogenous enzymes that catalyze the hydrolysis of monophosphate esters at alkaline $\mathrm{pH} .{ }^{15} \mathrm{ALP}$ is present in the serum in soluble form, but it is also found in many cellular membranes throughout the body. ${ }^{16}$

\section{MATERIALS AND METHODS}

The study was conducted in Al-Jumhori Teaching Hospital, Mosul, Iraq. It included twenty-two cholecystectomies performed at the laparoscopic unit over a period of 2 months started from July $1^{\text {st }}$ 2010 to September $1^{\text {st }} 2010$. Clinical details were retrieved from the records. The cholecystectomy specimens that were received were fixed in $10 \%$ formalin. The findings on gross examination were recorded. The stones were analyzed by chemical examination as described by Burtis and Aswood in 1999 and Tietz in 1986. Multiple sections were taken from each cholesterol stone-containing 
gallbladder (body, neck, and fundus) for paraffin blocks and were examined after staining with hematoxylin and eosin (H\&E).

Microscopic examination was done to assess the type of histological changes including inflammatory infiltrate, presence of fibrosis, cholesterolosis, metaplasia, tumor, or tumor-like lesion.

To evaluate the enzymatic activity of alkaline phosphatase, sections were stained using alkaline phosphatase stain (Gomori's method- Cobalt). ${ }^{17,18}$ Appropriate controls for the incubation were also run by omitting the substrates from the respective media.

To ensure maximum resolution of the histochemical reaction products for microscopy and to obtain optimal contrast in photomicrography, counterstaining was done in all the preparations using safranin.

\section{RESULTS}

Mean age of the patients was $50.5 \pm 2.1$ years (range 21-77), while the male:female ratio was 1:6.

Light microscopic examination of haematoxylin and eosin (H\&E) stained sections revealed that 13 $(59.09 \%)$ out of 22 cases had cholesterlosis (Figure 1), 3 (13.6\%) showed inflammation, and Rokitansky-Aschoff sinuses was noticed in 6 (27.27\%) (Figure 2).

The various histological abnormalities in gallbladder containing cholesterol stones with different frequencies are shown in Table 1.

By using alkaline phosphatase stain (Gomori's method-Cobalt), the amount of alkaline phosphatase activity varied considerably among the different areas in the same section, and often among different areas of the same layer of gallbladder, thus making the assessment difficult.

As shown in Figure 3 there is weak reaction to ALP stain in the mucosa of gallbladder as noticed in $8(36.36 \%)$ out of 22 cases. Figures $2 \& 4$ show moderate reaction to that stain accompanied with Rokitansky-Aschoff sinuses and cholesterlosis, the moderate activity of ALP stain was noticed in 14 (63.63\%) cases.

Some cases of cholelithiasis showed moderate to marked reaction of the mucosa and perimuscular layers to ALP stain as shown in Figure 5.

Some sections showed moderate reaction to ALP stain in the wall of the blood vessels (Figure 6).
The reaction of the various gallbladder layers to ALP stain was shown in Table 2.

Figure 1. A photomicrograph of gallbladder containing

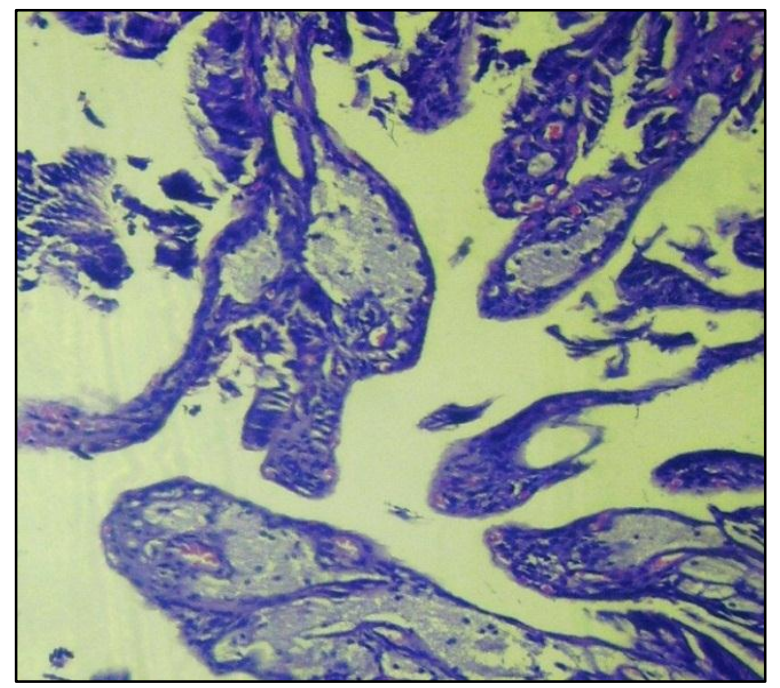

cholesterol stone showed cholesterlosis. (H\&E x 250).

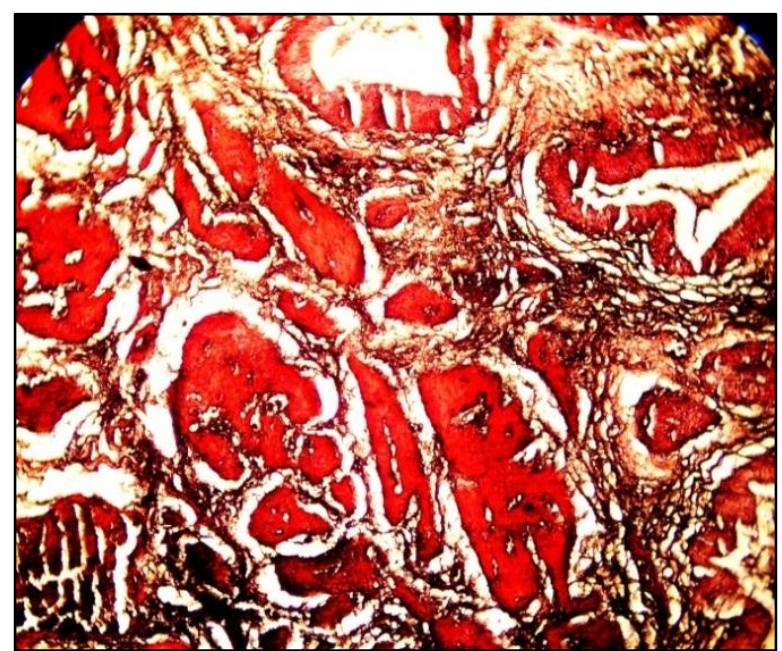

Figure 2. A photomicrograph of gallbladder containing cholesterol stone showed Rokitansky-Aschoff sinuses with moderate reaction to ALP stain. (ALPx400).

Table 1. The frequencies of different histological abnormalities.

\begin{tabular}{lc}
\hline \multicolumn{1}{c}{ Histological Findings } & Frequency (No.=22) \\
\hline Normal & $0(0.0 \%)$ \\
Cholerterosis & $13(59.09 \%)$ \\
Rokitansky-Aschoff Sinuses & $6(27.27 \%)$ \\
Inflammation & $3(13.6 \%)$ \\
\hline
\end{tabular}

Table 2. The reaction of different layers of gallbladder to ALP stain.

\begin{tabular}{lc}
\hline \multicolumn{1}{c}{ Site } & ALP \\
\hline Mucosa & $++/+++$ \\
Fibromuscular layer & $+/++$ \\
Perimuscular layer & ++ \\
\hline
\end{tabular}


+++, markedly positive; ++, moderately positive; +, weakly positive; -, negative.

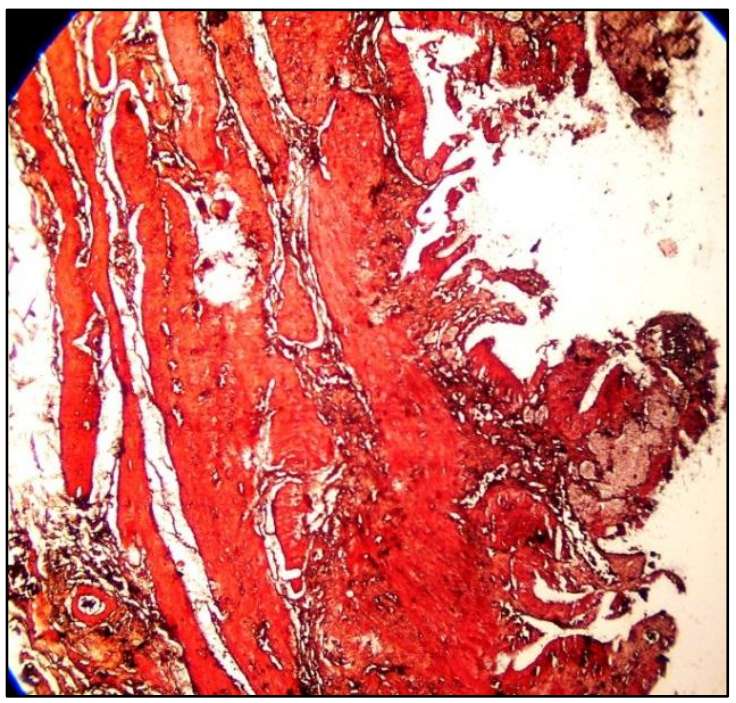

Figure 3. A photomicrograph of gallbladder containing cholesterol stone showed weak reaction to ALP stain. (ALPX250).

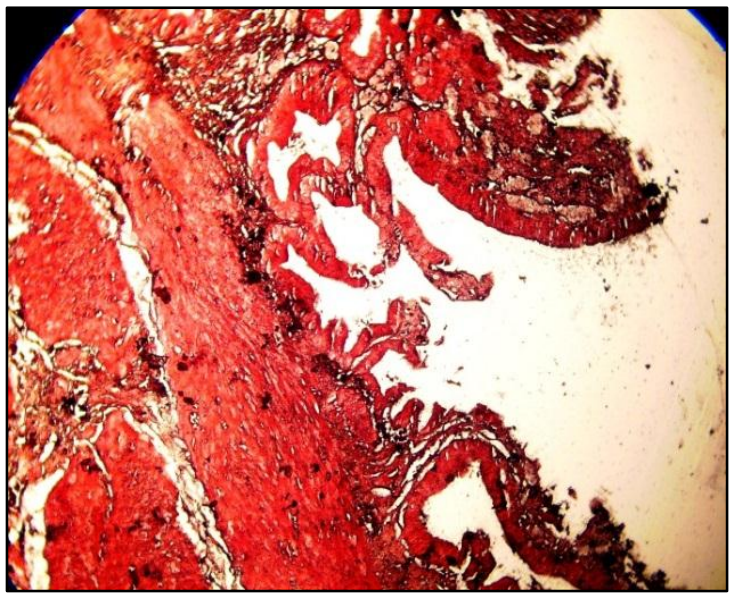

Figure 4. A photomicrograph of gallbladder containing cholesterol stone showed cholesterlosis and moderate reaction to ALP stain. (ALP $\times 250)$.

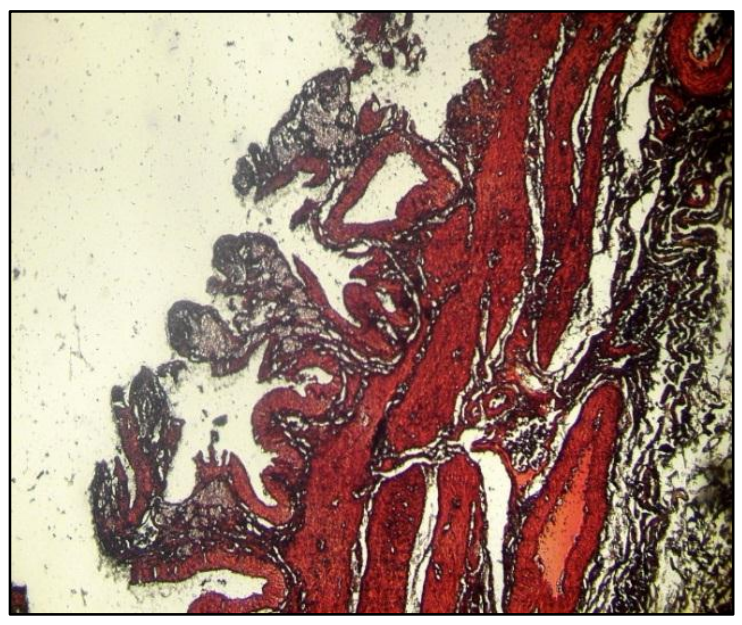

Figure 5. A photomicrograph of gallbladder containing cholesterol stone showed cholesterlosis and moderate to marked reaction to ALP stain in the mucosa and perimuscular layer. (ALP x 250).

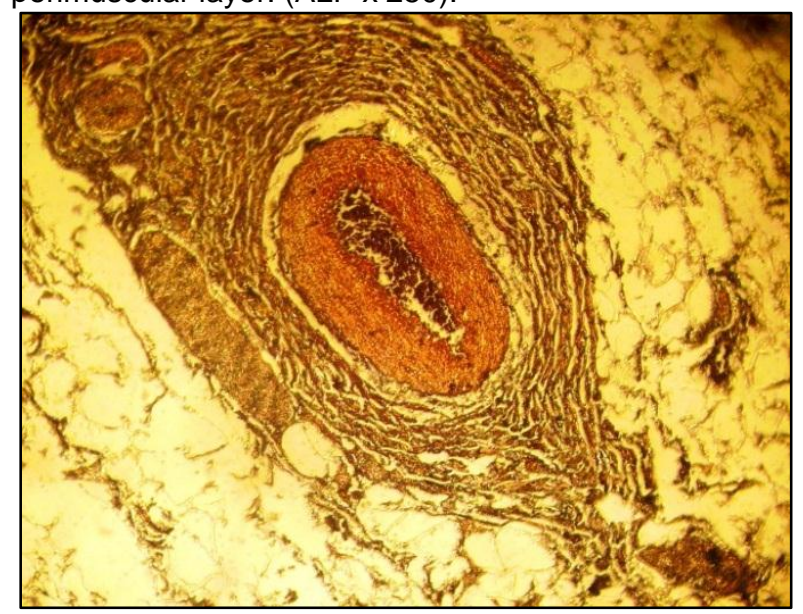

Figure 6. A photomicrograph of gallbladder containing cholesterol stone showed moderate reaction to ALP stain in the wall of the blood vessels. (ALP x 400).

\section{DISCUSSION}

Alkaline phosphatase has been shown to play an important but ill-defined role in transmembrane transfer mechanism as the enzyme is found primarily in cell membrane where active transport processes take place. ${ }^{19-21}$

The serum ALP is a measure of the integrity of the hepatobiliary system, however, it's wide spread in many tissues and fluids throughout the body gives its broad diagnostic potential. ${ }^{16,22,23}$

This study revealed that large number of patients was between 35 and 45 years, and male to female ratio was 1:6. These findings are in accord with Schirmer et al in 2005, ${ }^{24}$ Mohan et al in 2005, ${ }^{25}$ and Al-Khayatt et al in $2009,{ }^{26}$ who have also shown predominance of females among patients with gallstone diseases due to the effects of female sex hormones. Our results are consistent with those of Mohan et al in $2005^{25}$ who attributed the decrease in activity of cholesterol a reductase, and increase in activity of $\mathrm{HMG}$ CoA reductase to increased cholesterol secretion and saturation of bile.

Cholesterlosis was found to be the most frequent lesion mainly in the corpus and fundus, similar to the findings of Shcherbinina et al in $2007^{27}$ and Mohan et al in 2005. ${ }^{25}$

This study showed that ALP activity varied considerably among the different areas in the same section, and often among different areas of the same layer of gallbladder, thus making the 
assessment difficult. These findings are comparable to those of Saxena and Murthy, $2005,{ }^{22}$ Mangal et al in $2005,{ }^{20}$ and Al-Allaf in 2009. ${ }^{29}$

There are many contradictory views concerning the ALP activity in several disorders. This study showed that the moderate activity of ALP stain was noticed in 14 (63.63\%) cases. These findings are consistent with that of Mangal et al in $2005{ }^{20}$ who reported an increased ALP attributed to tissue ischemia, He suggested that there is considerable increase in lysosomal activity, presumably as a response to tissue ischemia and which by altering the tissue $\mathrm{pH}$ of cells, stimulates lysosomal activity which leads to cellular damage and destruction, with the release of ALP from vesicles into cytoplasm. This high intensity of ALP may be due to increased synthesis of this enzyme which could be a compensatory mechanism. ${ }^{20,27}$

We noticed moderate activity of ALP around the wall of blood vessels, these findings are similar to those of Saxena and Murthy in $2005^{22}$ and that of Al-Allaf in $2009 .^{29}$ They reported that strong activity of ALP was found in the adventitial layers of blood vessels and even capillary endothelium. They reported that the distribution of this enzyme on the cellular surface and cytoplasm, vascular adventitia and capillary endothelium may provide indication that the enzyme might participate in the transport of substances across the membranes.

Weak reaction to ALP stain in the mucosa of gallbladder was noticed in $8(36.36 \%)$ out of 22 cases, which is similar to that of Geetha in $2002{ }^{30}$ who reported that the activities of functional enzymes in mucosa such as ALP, $\mathrm{Na}(+)-\mathrm{K}+$ (EC 3.6.1.3) and $\mathrm{Ca}+$ (EC 3.6.1.2) adenosine triphosphatase showed significant decrease, however, there are differences in the used staining methods and sample size. In addition, his histopathological observation showed lipid accumulation, dilated blood vessels, necrotic and fibrotic changes and inflammation in the gallbladder mucosa of gall stone patients. He suggested that there is a high level of oxidative stress in the gall bladder mucosa in cases of gall stones, a finding that may be related to a decreased activity of functional enzymes in mucosal cells. Such a condition might result in an altered gallbladder absorption and secretion of bile components such as mucins and glycoproteins.
The resultant increased risk of bile saturation would further contribute to the progress of gall stone formation. ${ }^{26,30}$ In addition, Saxena and Murthy, ${ }^{22}$ reported that the overall decrease in the ALP activity in some cases indicates an impairment in the cellular transport mechanism. Futural studies will be recommended to define the localization of ALP with different gallbladder disorders especially on the levels of electron microscope, immunohistochemistry, and biomolecular lines. ${ }^{31,32}$

Acknowledgements: The authors are grateful to the staff of the Al-Jumhori Teaching Hospital Mosul, Iraq for their kind cooperation, which made this work possible. The authors would like to thank the staff of Histopathology Unit, Laboratory of Al-Jumhori Teaching Hospital for their help in facilitating this work. We would like to express our sincere gratitude to Miss Lumyaa Zaghlool, Department of Anatomy, College of Medicine for her excellent technical comments.

\section{REFERENCES}

1. Wang $\mathrm{HH}$, Portincasa $\mathrm{P}$, Wang $\mathrm{DQ}$. Molecular pathophysiology and physical chemistry of cholesterol gallstones. Front Biosci. 2008 Jan 1;13:401-423.

2. Channa NA, Khand FD, Khand TU, Leghari $M H$, Memon AN. Analysis of human gallstones by fourier transform infrared (FTIR). Pak Med Sci 2007; 23(4):546550.

3. Kleiner O, Ramesh J, Huleihel M, et al. A comparative study of gallstones from children and adults using FTIR spectroscopy and fluorescence microscopy. BMC Gastroenterol 2002;2:3-15.

4. Lee KT, Sheen PC. The ultrastructural study on epithelium of gallbladder with gallstones. Kaohsiung $\mathrm{J}$ Med Sci.1996;12(1):7-11.

5. Ganesh IM, Subramani D, Halagowder D. Mucin glycoarray in gastric and gallbladder epithelia. J Carcinog. 2007; 6: 10.

6. Madrid JF, Hernández F, Ballesta J. Characterization of glycoproteins in the epithelial cells of human and other mammalian gallbladder: A review. Microsc Res Tech. 1997;38:616-630.

7. LaMont JT, Turner BS, DiBenedetto D, Handin R, Schaefer Al. Arachidonic acid stimulates mucin secretion in prairie dog gallbladder. Am J Physiol 1983;245:G92G98.

8. Lee SP, LaMont JT, Carey MC. Role of gallbladder mucus hypersecretion in the evolution of cholesterol gallstones: studies in the prairie dog. J Clin Invest 1981;67:1712-1723.

9. Simon JA, Hudes ES. Serum Ascorbic Acid and Gallbladder Disease Prevalence Among US Adults Arch Intern Med 2000;160(7):931-936.

10. La Mont JT, Smith BF, Moore JR. Role of gallbladder mucin in pathophysiology of gall stones. Hepatology 1984;4(5):51-56.

11. Afdhal $\mathrm{NH}$, Ostrow JD, Koehler R, et al. Interaction of bovine gallbladder mucin and calcium-binding protein: 
effects on calcium phosphate precipitation. Gastroenterology 1995 Nov;109(5):1661-1672.

12. Lee SP, Lamount JT, Carey MC. Role of gallbladder mucus hypersecretion in the evolution of cholesterol gallstones. J Clin Inves 1981; 67(6):1712-1723.

13. Klaunig JE, Xu Y, Isenberg JS, et al. The Role of Oxidative Stress in Chemical Carcinogenesis. Environmental Health Perspectives Supplements.1998; 106 (S1):289-295.

14. Barber DA, Harris SR. Oxygen free radicals and antioxidants: a review. Am Pharm. 1994; 34:26-35.

15. Syakalima M, Takiguchi M, Yasuda J, Hashimoto A. The canine alkaline phosphatase: a review of the isoenzymes in serum, analytical methods and their diagnostic application. Jpn J Vet Res.1998; 46:3-11.

16. Fernandez NJ, Kidney B. Alkaline phosphatase: beyond the liver. Vet Clin Pathol. 2007; 36:223-233.

17. Waters SE, Butcher RG. Studies on the Gomori acid phosphatase reaction. Histochem J 1980;12:191-200.

18. Pearse AGE. Histochemistry: theoretical and applied, $v$ I: preparative and optical technology. $3^{\text {rd }}$ ed. London: J\&A Churchill; 1968. p.759.

19. Harris $H$. The human alkaline phosphatase :what we know and do not. Clin Chim Acta.1989; 186:133-150.

20. Mangal A, Shrivastava P, Gaur U, Jain A, Goyal U, Rath G. Histochemical analysis of placental alkaline phosphatase in hypertensive disorders complicating pregnancy . Journal of the Anatomical Society of India 2005; 54( 2):1-10.

21. Palmer T. Some applications of enzymatic analysis in medicine and industry. Enzymes: biochemistry, biotechnology, clinical chemistry. $1^{\text {st }}$ ed. England: Horword Publishing Ltd; 2001. p. 340-351.

22. Saxena N, Murthy PSR. Hydrolytic enzyme activity in rhesus monkey placenta during early gestational malaria: histochemical studies. J Vect Borne Dis 2005; 42:135-140.
23. Roberts JM, Cooper DW. Pathogenesis and genetics of pre-eclampsia. Lancet 2001;357:53-56.

24. Schirmer BD, Winters KL, Edlich RF. Cholelithiasis and cholecystitis. J Long Term Eff Med Implants 2005; 15(3):329-338.

25. Mohan H, Punia R P S, Dhawan SB, Ahal S, Sekhon MS. Morphological spectrum of gall stone disease in 1100 cholecystectomies in North India. Indian journal of surgery 2005;67(3):140-142.

26. Al-Khayatt M K, Al-Allaf LIK, Al-Jewary A H. A study of Histochemical Alteration of Mucin in Cases of Cholelithiasis and Gallbladder Tumors. The Sixth Scientific conference Proceedings, Nursing College, Mosul University. June 2009. p.101-116.

27. Shcherbinina MB, Zakrevskaya YV, Korolenko AS, Lymar LI. Cholesterolosis and chronic cholecystitis: comperative analysis of state of gall-bladder wall. МОРФОЛОГІЯ. 2007; І (3):94-100.

28. Baig SJ, Biswas S, Das S, Basu K, Chattopadhyay G. Histopathological changes in gall bladder mucosa in cholelithiasis: correlation with chemical composition of gallstones. Tropical Gastroenterol 2002;23:25-27.

29. Al- Allaf LIK. Histochemical analysis of placental phosphatases in cases of preterm preeclampsia. Duhok Medical Journal 2009; 3(2):52-66.

30. Geetha A. Evidence for oxidative stress in the gall bladder mucosa of gall stone patients. The Journal of Biochemistry, Molecular Biology and Biophysics 2002;6 (6):427-432.

31. Hamilton-Dutoit SJ, Lou H, Pallesen G. The expression of placental alkaline phosphatase (PLAP) and PLAP-like enzymes in normal and neoplastic human tissues. An immunohistological survey using monoclonal antibodies. APMIS 1990;98:797-811

32. Nardi M JR, Perri SG, Pietrangeli $F$, et al. "Sequential" treatment: is it the best alternative in cholecysto-choledochal lithiasis?. Chir Ital 2002;54(6): 785-798. 